\title{
Estuarine sediment deposition during wetland restoration: A GIS and remote sensing modeling approach
}

\author{
Michelle Newcomer: San Francisco State University, NASA DEVELOP Program \\ Amber Kuss: San Francisco State University, NASA DEVELOP Program \\ Tyler Ketron: Stanford University, NASA DEVELOP Program \\ Alex Remar: Cal Poly San Luis Obispo, NASA DEVELOP Program \\ Vivek Choksi: Gunn High School, NASA DEVELOP Program \\ J. W. Skiles: Ph.D., NASA Ames Research Center \\ NASA Ames Research Center: DEVELOP National Program \\ M.S. 242-4 Moffett Field, California 94035 \\ Office: 650-604-3237 Fax: 650-604-7254 \\ Corresponding authors: Michelle.E.Newcomer@nasa.gov \\ Joseph.Skiles@nasa.gov
}

Keywords: suspended sediment concentration, remote sensing, MARSED, wetlands, GIS

\begin{abstract}
Restoration of the industrial salt flats in the San Francisco Bay, California is an ongoing wetland rehabilitation project. Remote sensing maps of suspended sediment concentration, and other GIS predictor variables were used to model sediment deposition within these recently restored ponds. Suspended sediment concentrations were calibrated to reflectance values from Landsat TM 5 and ASTER using three statistical techniques-linear regression, multivariate regression, and an Artificial Neural Network (ANN), to map suspended sediment concentrations. Multivariate and ANN regressions using ASTER proved to be the most accurate methods, yielding $\mathrm{r}^{2}$ values of 0.88 and 0.87 , respectively. Predictor variables such as sediment grain size and tidal frequency were used in the Marsh Sedimentation (MARSED) model for predicting deposition rates for three years. MARSED results for a fully restored pond show a root mean square deviation (RMSD) of $66.8 \mathrm{~mm}(<1 \sigma)$ between modeled and field observations. This model was further applied to a pond breached in November 2010 and indicated that the recently breached pond will reach equilibrium levels after 60 months of tidal inundation.
\end{abstract}




\section{Introduction}

Development of the San Francisco Bay Estuary during the last 200 years has transformed nearly $90 \%$ of historical wetland habitats into agricultural fields and industrial salt production ponds (Philip Williams \& Associates Ltd. and Faber 2004). The South Bay Salt Pond Restoration Project (SBSPRP), the largest and most complex wetland restoration effort on the West Coast of the United States, will convert approximately 6070 hectares of salt production ponds to restored wetland habitats (Takekawa et al. 2005). Understanding long-term sediment dynamics within the South Bay is critical for proper accumulation estimates and subsequent restoration management strategies in newly breached salt ponds (Foxgrover et al. 2007; Trulio et al. 2007). Sediment accumulation rates of breached salt ponds are directly influenced by suspended sediment concentrations (SSCs), water flow paths, and tidally-driven sediment re-suspension (Philip Williams \& Associates Ltd. and Faber 2004). Marshland rise within the breached salt ponds allows plant colonization and establishment of a healthy wetland ecosystem (Philip Williams \& Associates Ltd. 2005). Continued monitoring of estuarine sediment accumulation will provide temporal and spatial development predictions for each phase of the restoration process.

\section{Materials and Methods}

Study Site

Tidal marshes are some of the most highly productive ecosystems on the planet (Kelly and Tuxen 2009). The South Bay salt ponds, located at the southern end of San Francisco Bay (Figure 1), lie on the Pacific flyway, providing roosting and over-wintering sites for migratory bird species, and habitat for waterfowl, shorebirds, and mammals (Siegel and Bachand 2002). Fresh water enters the south bay through the Coyote Creek Tributary and also delivers sediment to the Alviso Ponds. In March of 2006, the U.S. Fish and Wildife Service (USFWS) Don Edwards National Wildlife Refuge and the Santa Clara Valley Water District initiated tidal pond inundation in Pond A21 (Callaway et al. 2009). The levees of the Pond A21 (Figure 1) were breached allowing daily tidal flow for the first time in over 100 years with the goal of providing natural sedimentation processes to restore the tidal marsh habitat for successful vegetation reestablishment (Callaway et al. 2009). 
Experimental Design

Sediment deposition was modeled for Pond A21 for the three years after the levees were breached in March, 2006 (Figure 1) (Newcomer et al. 2011). The model was further applied to Pond A6 (discussed below) following the methods outlined by Newcomer et al. (2011). Pond A6 was breached in November 2010 and a high tide satellite image was obtained in January 2011. Sediment deposition is a function of the SSC, settling velocity, bulk density, and water velocity (Temmerman et al. 2004). Temmerman et al. (2003) modified an algorithm developed by Krone (1987) to predict sediment deposition using these known variables, and was able to predict sediment deposition in growing marsh ecosystems at point locations of known SSC. This study used point locations of SSC to calibrate satellite imagery, providing a spatially comprehensive distribution of SSCs within Pond A21 and Pond A6. Accurately mapping SSCs from remotely sensed images provided a method for determining sediment concentrations without disturbing ecologically sensitive areas.

Satellite image processing has previously been used to calibrate image-based reflectance values to in-situ measurements of SSCs in the visible and near-infrared spectral range (Munday and Alföldi 1979; Chen et al. 1992; Baban, 1995; Miller and McKee 2004; Chen et al. 2006). Previous studies report moderately strong correlations between reflectance values and turbidity using a linear analysis (another measure of suspended sediment) in the 600-700 nm range $\left(r^{2}=0.72\right)$ (Miller and McKee 2004; Chen et al. 2006) while other studies report strong correlations in the 600-900 $\mathrm{nm}$ range $\left(\mathrm{r}^{2}=0.79\right)$ using a linear and multivariate analysis (Pavelsky and Smith, 2009).

Two different satellite sensors - the Landsat-5 Thematic Mapper (TM), and the Advanced Spaceborne Thermal Emission and Reflection Radiometer (ASTER) — were used in this study to map suspended sediment in the South San Francisco Bay (WIST 2010; USGS 2010a). Reflectance values were statistically correlated with SSCs from in-situ field data collected during the summer of 2010 and from the USGS Water Quality Dataset (USGS 2010b). Linear regression, multivariate regression, and an Artificial Neural Network (ANN) were used to correlate pixel reflectance values with corresponding SSC measurements. Additional inputs of seasonal variations in SSCs, distance from the levee breech, bulk density, settling velocity, initial marsh height, time of inundation, tidal frequency, and a high-volume array of SSC data points (obtained from the satellite-produced images) were used in the MARSED model for sediment accumulation. 
Care was taken to create accurate SSC maps because this variable highly influences sediment deposition. The three different regression techniques thus ensured that the regression chosen would most accurately represent sediment concentrations for any day throughout the year. After calibrating the satellite imagery using the regression equations, the SSC maps were input into the MARSED model to predict deposition in Pond A21 for three years post-breach. Modeled marsh accumulation values were then compared to previously documented point measurements of sediment accumulation heights in the breached Pond A21 (Callaway et al. 2009) to assess model accuracy. Pond A21 was used in the model due to the previously acquired point measurements provided in Callaway et al. (2009), which provided a baseline for comparison with the modeled estimates. Once the modeled values for Pond A21 were within reasonable tolerance $( \pm 10 \%)$ to previously documented point measurements, the model was used to predict deposition for Pond A6 which was breeched in November 2010.

Satellite Remote Sensing

All satellite imagery was radiometrically corrected to reflectance and re-projected to the UTM WGS 84 North projection to ensure tonal and spatial comparability between each scene. To create SSC maps, Landsat TM 5 and ASTER images were first imported into a Geographical Information System (ArcGIS). Reflectance values from Band 1, 2, and 3 of ASTER (520-600 nm, 603-690 nm, 780-860 nm respectively) were calibrated with SSC values using two scenes (Table 1). Reflectance values from Band 1, 2, 3 and 4 of Landsat TM 5 (450-520 nm, 520-600 $\mathrm{nm}, 630-690 \mathrm{~nm}, 760-900 \mathrm{~nm}$ respectively) were calibrated with SSC values using five scenes (Table 1). Linear, multivariate, and ANN regressions were compiled for both sensors to determine the best statistical technique for correlation with SSCs. Imagery was calibrated using data from the historical USGS Water Quality of San Francisco Bay monitoring program (USGS 2007; USGS 2010b) and from our field samples. The scenes chosen in Table 1 were based on the availability of an overpass that corresponded with a cloud-free day and correlated with the day of the historical USGS samples and our field samples. Values were determined at both the original resolution and at an averaged resolution (a $3 \times 3$ grid) to reduce signal noise.

Field Methods

Various studies have developed methods for monitoring in-situ sediment accumulation rates, with a widerange of techniques and accuracy. Installed monitoring devices such as: sediment traps (Gardner et al. 1980; Bale 
1998), graduated pins (Reed 1989; Cahoon and Lynch 1997; Callaway et al. 2009), anchored tiles (Reed 1989; Pasternack and Brush 1998), and sediment erosion tables (SETs) (Boumans and Day 1993; Childers et al. 1993; Cahoon et al. 2002) are inexpensive and effective methods for estimating accumulation rates, but provide limited sampling points. SSC estimates are often used to indirectly measure sediment accumulation rates, and can be obtained through in-situ measurements and remote sensing techniques (Stumpf and Pennock 1989; Froidefond et al. 1993; Ruhl et al. 2001; Li et al. 2003; Miller and McKee 2004).

Surface water samples for suspended sediment analysis were collected at 24 random locations in the South Bay over the course of two field days that corresponded with Landsat and ASTER overpasses. Sampling sites were also chosen in locations of the deep water channel where the boat would not affect SSC values. Samples were processed at the USGS Western Coastal and Marine Geology Laboratory (WCMGL) to determine SSC values. In addition, sediment samples were collected from Pond A21 to characterize the physical properties of sediment in the South Bay. These samples were taken at five representative locations along the perimeter and seven locations on the interior of the pond. Each sample was processed at the WCMGL for grain size distribution, settling velocity, and organic content (Table 2). A value for bulk density was generated from a reference density data set of clay and mud densities (SI Metric, 2009). These characteristics, along with SSCs, are inputs to the MARSED model (Temmerman et al. 2003; Temmerman et al. 2004).

\section{USGS Continuous Monitoring Stations and Monthly Cruises}

In addition to the field collected SSC samples, historical SSC datasets were obtained from the USGS's Water Quality and Continuous Monitoring Stations of San Francisco Bay database for sampling stations 30 to 36, south of the San Mateo Bridge (USGS 2007;USGS 2010b). These additional datasets provided us with a more comprehensive set of SSC values for which to correlate with the satellite images from 1994, 2007, and 2009. Outliers due to sensor interference from biological fouling, especially during summer months, were excluded (Buchanan and Lionberger 2007). Additionally, these datasets were also used to calculate seasonal trends of sediment influx to the South Bay. Seasonal mean averages were computed and compared to the 10-year average of $35.20 \mathrm{mg} / \mathrm{L}$. The ratio between seasonal average SSCs and the 10-year average was calculated to be 1.08 for winter, 1.16 for spring, 0.95 for summer, and 0.81 for fall. This seasonal variation in SSCs can be explained by high rainfall in the winter and spring (NCDC 2010). Resuspension of sediments may have also contributed to higher 
concentrations in the spring and summer months, due to stronger winds in the South Bay (Buchanan and Lionberger 2007). These coefficients were applied to seasonally adjust predicted SSCs for input into the MARSED model.

Marsh Sediment Deposition Model (MARSED)

A goal of this study was to model sediment deposition in Pond A21 (Figure 1) and compare modeled results with the field dataset for sediment deposition collected by Callaway et al. (2009). Modeling techniques can be used to estimate future sediment accumulation rates and account for factors including wetland age, surface elevation, and sea level fluctuations (Allen, 1990; French and Spencer 1993; French et al. 1995; Allen 1997; Temmerman et al. 2003; Temmerman et al. 2004). A zero-dimensional time-stepping marsh sediment deposition model (MARSED) has been used to predict wetland development based on particle settling velocity, time dependant SSCs, and sediment bulk density (Krone 1987; Temmerman et al. 2003; Temmerman et al. 2004). To effectively model sediment accumulation over several tidal cycles and years, the MARSED model developed by Krone (1987), and modified by Temmerman et al. (2004), was implemented using a GIS to predict sediment accumulation for Pond A21, and then an accuracy assessment was run to verify simulated results from Equation 1.

$$
\frac{d E}{d t}=\frac{d S(\text { grain })}{d t}+\frac{d S(\text { organic })}{d t}-\frac{d P}{d t}
$$

Where:

$d E / d t=$ rate of marsh height rise $(\mathrm{m} /$ year $)$

$d S$ (grain) $/ d t=$ rate of mineral sediment deposition $(\mathrm{m} /$ year $)$

$d S($ organic $) / d t=$ rate of organic content deposition $(\mathrm{m} /$ year $)$

$d P / d t=$ resuspension/compaction $(\mathrm{m} /$ year $)$

Equation 1 was solved for $d E / d t$ by summing the rates of deposition for mineral sediment and organic content and subtracting resuspension and compaction. Organic content was obtained from laboratory analysis and solving for the addition of sediment grains, $d S$ (grain)/dt, required further calculation in Equation 2 . Equation 2 provides the total grain deposition by calculating deposition for each tidal cycle and subsequently for each year. 
Equation 2 produced a final estimate of marsh evolution during the three years post-breach as a function of sediment concentration, settling velocity, and bulk density of the sediment grains (Krone 1987).

$$
\frac{d S(\text { grain })}{d t}=\int_{\text {Year }} \int_{\text {Tide }} \frac{w_{s}^{*} C(t)^{*} d t}{\rho}
$$

Where:

$d S($ grain $) / d t=$ rate of mineral sediment deposition $(\mathrm{m} /$ year $)$

$w_{s}=$ particle settling velocity $(\mathrm{m} / \mathrm{s})$

$C(t)=$ time dependant sediment concentration from Equation $3\left(\mathrm{~kg} / \mathrm{m}^{3}\right)$, obtained using remote sensing $\rho=$ bulk density $\left(\mathrm{kg} / \mathrm{m}^{3}\right)$

To obtain the $C(t)$ term in Equation 2, the initial concentration value $C(0)$ was taken from the remotely sensed image, and then Equation 3 was solved for $d C / d t$ for initial conditions at $t=0$. Euler's Method was used for solving the equation by iteration through each time step to obtain the final $C(t)$ at each time step until the solution reached a steady-state value. To initially model the changing sediment concentration with the incoming tide, Equation 3 was solved at time steps of $\mathrm{t}=0.001 \mathrm{~s}$ in Matlab (Krone, 1987; Temmerman et al. 2003).

$$
[h(t)-E] \frac{d C}{d t}=-w_{s} C(t)+[C(0)-C(t)] \frac{d h}{d t}
$$

Where:

$h(t)=$ time dependant water surface elevation $(\mathrm{m})$

$E=$ Elevation of the marsh surface (m)

$d C / d t=$ rate of sediment concentration change $(\mathrm{kg} / \mathrm{s})$

$w_{s}=$ particle settling velocity $(\mathrm{m} / \mathrm{s})$

$C(t)=$ time dependant sediment concentration $\left(\mathrm{kg} / \mathrm{m}^{3}\right)$

$C(0)=$ initial sediment concentration $\left(\mathrm{kg} / \mathrm{m}^{3}\right)$

$d h / d t=$ velocity of incoming flood tide $(\mathrm{m} / \mathrm{s})$ 
For the purposes of this study, the Euler method yielded a sufficient approximation to the final SSC value. The numerical approximation for solving Equation 3 at time steps of $\mathrm{t}=0.001 \mathrm{~s}$ and $60,000+$ iterations ensured a steadystate solution was reached. Euler's method was appropriate for solving Equation 3 because the Euler global error is proportional to the precision of the time step — approximately $\pm 0.001 \mathrm{mg} / \mathrm{L}$ in this case (Zill and Cullen 2009). This error is insignificant to the overall SSC values because the accuracy of the laboratory-derived SSC is $\pm 0.01 \mathrm{mg} / \mathrm{L}$.

The conceptual framework of the MARSED model includes all inputs that directly affect marsh sedimentation, and were applied to the GIS model (Figure 2). SSC was the most influential variable in this study and was calculated using an algorithm applied to the remote sensing images. For each pixel, a correlating SSC value was used as the initial condition $(C(0))$ and was used in Equation 3 to determine the final rate of concentration change $(d C / d t)$. Once the rate of concentration change was obtained, the concentration at any specific time thereafter could be solved.

\section{Statistical Analysis}

Three different statistical techniques were used to establish correlations between a range of SSC values $(0$ $100 \mathrm{mg} / \mathrm{L}$ ) and satellite reflectance values (Teodoro et al. 2008) — linear regression, multivariate regression, and an ANN. For linear regressions, the band that produced the best statistical correlation for each sensor was determined and then used in subsequent calculations. For multivariate regressions and artificial neural networks, all available visible and near-infrared bands were used. The ANN was implemented using an adaptive linear combiner (Wilde 2009). The ANN estimates the SSC by multiplying each band by a weight. After each iteration, the residual is calculated, and the weights are adjusted until the error is minimized. Essentially, the ANN takes the data and learns from it until it produces the lowest possible error. Field SSC measurements as well as data from the USGS's Water Quality of the San Francisco Bay Project were correlated with reflectance values from multiple satellite images using all of these statistical techniques (USGS 2010b). The final values contained in the SSC maps were then used in the MARSED model for predicting sediment deposition.

\section{Results}


Field and Laboratory Results

The field samples were processed at the USGS WCMGL. The average values from this analysis that were used in the MARSED model are shown in Table 3 (Newcomer et al. 2011). Average surface SSCs for Pond A21 were $46.16 \mathrm{mg} / \mathrm{L}$. This is consistent with the values provided by the multivariate regression for Pond A21 using the satellite images. This field validation of the multivariate correlation is another source of information that provides the best possible SSC map for input into the MARSED model. The low organic content of sediment in our samples can be attributed to the fact that Pond A21 is a continuously developing marsh with little biological activity. The sediment is dominated by clay sized particles-92\% of particle diameters fall below $16 \mu \mathrm{m}$ (Krumbein and Sloss 1963).

Suspended Sediment Prediction Results

The accuracy of detecting SSCs through the use of remote sensing is dependent on many factors including the resolution of the satellite image, the ability to acquire and process the image with corresponding in-situ SSC values, and hydrodynamic influences. The two remote sensing instruments used in this study (ASTER and Landsat TM 5) show varying accuracy in correlating reflectance values with SSCs (Table 4). Reflectance values in clear water are generally zero, and predictably increase with increasing SSCs (Figure 3) as also shown by Li et al. (2003). Regressions effectively correlated pixel values with SSCs in each of the sensors, and were subsequently applied to each image in ArcGIS to create a suspended sediment map. The most effective linear regression for SSC correlations from ASTER and Landsat TM 5 was band $3(630-690 \mathrm{~nm})$ (Table 3). Multivariate and ANN regressions using ASTER imagery proved to be the most accurate correlation method, yielding $\mathrm{r}^{2}$ values of 0.88 and 0.87, respectively (Table 3). The $15 \mathrm{~m}$ resolution of ASTER produced the most accurate results in correlating SSCs. The low linear regression value for ASTER can be attributed to the lack of field data for the overpass of the ASTER sensor. 


\section{GIS Model Results}

Root mean square deviation (RMSD) was used to measure the difference between marsh accumulation values computed by the model and field values collected by Callaway et al. (2009) (Table 4). Linear regression with band 3 of ASTER provided the most accurate results, yielding a RMSD of $66.84 \mathrm{~mm}$ (Table 4). This is less than 3 inches of deviation, providing reasonable error and accuracy for predicting marsh sedimentation at local ponds in the South Bay.

\section{Predicting Deposition in Pond A6}

The MARSED model was applied to Pond A6 in the Alviso complex, which was breached in the November of 2010 (Figure 4). A January 5, 2011 Landsat TM5 image was used to map SSCs because of an overpass on a day of high tide. An initial run of the model with the same rates of deposition and initial conditions as for Pond A21 did not yield marsh equilibrium levels to provide a stable habitat for vegetation colonization within a 36-month time frame. The model was then run for a longer time frame, yielding equilibrium levels after 60 months. One interpretation is that a longer time frame was necessary because SSCs are consistently lower (by about half) around A6 than around A21, leaving less sediment for deposition and resulting in lower marsh accumulation rates in A6. The location of the levee breaches also factored into the longer time frame for marsh establishment in A6 (Figure 4). Pond A6 has two breaches along a slough divergent from the relatively calm Coyote Creek, as well as two breaches connecting the Pond to the relatively strong tidal currents of the South Bay. The tidal influences from the breach on the west side of Pond A6 may increase the potential for erosion and further inhibit marsh accumulation from the rates observed in Pond A21. The initial height of Pond A6 also factors into the time-frame required for the marsh to reach equilibrium. Pond A6 has experienced much more subsidence and compaction than other ponds and initially had lower elevations. The lower initial elevation of Pond A6 requires more sediment deposition to reach equilibrium.

\section{Model Sensitivity}

A sensitivity analysis of the MARSED model to different parameters was run to assess how some of the most important predictor variables change the trajectory of marsh equilibrium accumulation. The variables of tidal velocity, length of each time step, and the time-length of slack during one tidal cycle were considered. The modeled 
dataset was compared to the field dataset, and the sensitivity of the model to different tidal velocities was examined (Figure 5). The lowest tidal velocity was assumed for these areas because these areas are not influenced by wave action. The velocity of the incoming tide is important to the model, thus, three different model runs using different tidal velocities were considered (Figure 5). The field data line shows the true values for marsh accumulation over time measured by field parameters (Callaway et al. 2009). The high, medium, and low tidal velocity curves correspond to different marsh accumulation rates for each run. The incoming tidal velocity was estimated to be 7 $\mathrm{mm} / \mathrm{s}, 10 \mathrm{~mm} / \mathrm{s}$, and $12 \mathrm{~mm} / \mathrm{s}$ for the lowest, medium, and highest tidal velocities, respectively. These tidal velocities are slow relative to typical velocities of tides and to velocities outside of the pond breaches. Since the ponds fill up from multiple input points, we assumed that flow in through these inputs would sufficiently suppress the tidal velocity allowing for sediment accumulation. Small changes in the assumed tidal velocity produced significant changes in the accumulation. For example, the lowest tidal velocity produced the highest amount of marsh accumulation because sediments can only settle when conditions are at or near slack. For the final model run the lowest tidal velocity of $7 \mathrm{~mm} / \mathrm{s}$ was used.

Equation 3 was solved for each time step to retrieve the change in the SSC with time. The model is sensitive to the choice of the time-step used (Figure 6). A time-step of $5 \mathrm{~s}$ produces larger errors in the beginning, but eventually results in the same value as the other time steps. For this analysis, a time-step of $0.001 \mathrm{~s}$ was used. Because the time of accumulation of a marshland occurs at timescales much larger than those producing errors here, any time step could have been used.

Another variable that can significantly alter the output of the model is time that the water experiences slack. The period of slack is very important to marsh accumulation and without a significant amount of time for sediment to deposit, acceptable rates of marsh accumulation will not occur. Three different slack times produce varying amounts of deposition (Figure 7). A slack time of 0.5 hour produces less than half of the amount of deposition compared to a 1.5 hour slack time. A total time of slack was chosen to be 1.5 hours, due to the average slack time observed in the study area (NOAA, 2011).

\section{Discussion}

The MARSED model can accurately predict marsh sedimentation in the newly breached salt ponds in the South San Francisco Bay. The accuracy of the MARSED model is dependent on field data and GIS inputs. In the 
case for prediction using ASTER, the linear technique produced the lowest RMSD for the model, whereas multivariate regression produced the best correlation between SSC and reflectance (Table 4). Furthermore, linear regression, being the simplest statistical method used, was not expected to produce the most accurate marsh accumulation estimates. This discrepancy could have resulted from bias in the model, which systematically overestimated marsh accumulation. This overestimation most likely arose because the model does not account for compaction or resuspension of settled sediment processes, which inhibit marsh elevation rise. Resuspension may be wind-generated (driven by shear velocity and water depth) or tidally generated (when ebb tide moves water and sediment out of the ponds). The inherent error of the model can also be attributed to the deviation of the reflectance values from the true SSC values. Reflectance values are measured to the fifth decimal place, whereas SSCs are reported to the second decimal place. This discrepancy could result in multiple reflectance values for the same SSC value, thus increasing error in the analysis. The cumulative marsh sedimentation curve is shown in Figure 5 . The marsh initially rises rapidly, but sedimentation rates slow as the marsh sediment nears a stable height relative to sealevel that allows for vegetation colonization. The height of marsh growth will vary with the initial elevation of the pond, however once equilibrium with sea-level is reached, the marsh will no longer accumulate sediment.

Although the model produced applicable results to other wetland restoration efforts, outliers indicate a need for further assessment of environmental variables. Four outliers greatly underestimated sediment accumulation in the model, and were not included in the RMSD calculations. These outliers corresponded with locations along the southeastern perimeter of Pond A21, where unaccounted influences from the tidal channel and from pond geometry may have significantly heightened true marsh accumulation. When outliers were excluded, the model's RMSD of $66.84 \mathrm{~mm}$ fell within one standard deviation of actual accumulation values. Due to highly accurate depositional estimates, the model is a useful tool for studying future wetland restoration efforts, however the sensitivity of the model should be considered for future use in other wetland ecosystems.

\section{Conclusions}

In this study, suspended sediment concentrations were successfully calibrated to remote sensing reflectance values using three statistical techniques: linear regression, multivariate regression, and ANN regression. Multivariate correlations with ASTER provided the best $r^{2}$ value of 0.88 . The output suspended sediment maps were then used in the MARSED model to predict sediment deposition for Pond A21. Model results show excellent correlation with 
observed sedimentation rates from Pond A21 with a RMSD of $66.8 \mathrm{~mm}$ (approximately 2.6 inches). Overall, the model is an accurate predictor of sedimentation for the South San Francisco Bay salt ponds, and can be a useful and successful tool for future management decisions. These tools can aid restoration managers in deciding not only the ideal location for a breach, but can also provide time estimates for a newly breached pond to reach equilibrium levels.

\section{Acknowledgements}

This research was funded by the NASA DEVELOP National Program. We thank Dr. Randy Berthold, John Preston, and Matt Linton for making the NASA DART boats available for our sampling campaign. We also thank Dr. Mike Torresan and Angela Lam for providing the USGS facilities for our sediment analysis. We also thank Dr. Karen Grove, Erin Justice, Dr. Charles Williams, Brad Lobitz, and Dr. David Freyberg for their help and support with this project. The team also acknowledges the ASTER science team and the Landsat TM science team for providing the data and support. 


\section{References}

Allen, J., 1990. Salt-marsh growth and stratification: a numerical model with special reference to the Severn Estuary, southwest Britain, Marine Geology, 95: 77-96.

Allen, J., 1997. Simulation models of salt-marsh morphodynamics: some implications for high-intertidal sediment couplets related to sea-level change, Sedimentary Geology, 113: 211-223.

Baban, S. M. J., 1995. The use of Landsat imagery to map fluvial sediment discharge into coastal waters, Marine Geology, 123 (3-4): 263-270.

Bale, A., 1998. Sediment trap performance in tidal waters: comparison of cylindrical and conical collectors, Continental Shelf Research, 18(11): 1401-1418.

Boumans, R., and J. Day, 1993. High precision measurements of sediment elevation in shallow coastal areas using a sedimentation-erosion table, Estuaries and Coasts, 16(2): 375-380.

Buchanan, P., and M. A. Lionberger, 2007. Summary of suspended-sediment concentration data, San Francisco Bay, California, water year 2005, U.S. Geological Survey Data Series 282, Reston, VA, 49 pp.

Callaway, J. C., V. T. Parker, L. M. Schile, E. R. Herbert, and E. L. Borgnis, 2009. Dynamics of sediment accumulation in Pond A21 at the Island Ponds, California State Coastal Conservancy, Oakland, CA, 66 pp.

Cahoon, D. R., and J. C. Lynch, 1997. Vertical accretion and shallow subsidence in a mangrove forest of southwestern Florida, USA, Mangroves and Salt Marshes, 1(3): 173-186.

Cahoon, D., J. Lynch, P. Hensel, R. Boumans, B. Perez, B. Segura, and J. Day Jr., 2002. High-precision measurements of wetland sediment elevation: I. Recent improvements to the sedimentation-erosion table, Journal of Sedimentary Research, 72(5): 730-733.

Chen, Z., P. J. Curran, and J. D. Hansom, 1992. Derivative reflectance spectroscopy to estimate suspended sediment concentration, Remote Sensing of Environment, 40(1): 67-77.

Chen, Z., C. Hu, and F. Muller-Karger, 2006. Monitoring turbidity in Tampa Bay using MODIS/Aqua 250-m imagery, Remote Sensing of Environment, 109(2): 207-220.

Childers, D., F. Sklar, B. Drake, and T. Jordan, 1993. Seasonal measurements of sediment elevation in three midAtlantic estuaries, Journal of Coastal Research, 9(4): 986-1003.

Foxgrover, A., B. Jaffe, G. Hovis, C. Martin, J. Hubbard, M. Samant, and S. Sullivan, 2007. 2005 Hydrographic survey of South San Francisco Bay, California, Open-File Report, U.S. Geological Survey, 113 pp. 
French, J. R., and T. Spencer, 1993. Dynamics of sedimentation in a tide-dominated back-barrier salt marsh, Norfolk, UK, Marine Geology, 110(3-4): 315-331.

French, J. R., T. Spencer, A. L. Murray, and N. S. Arnold, 1995. Geostatistical analysis of sediment deposition in two small tidal wetlands, Norfolk, U.K., Journal of Coastal Research, 11(2): 308-321.

Froidefond, J. M., P. Castaing, J. M. Jouanneau, R. Prud'Homme, and A. Dinet, 1993. Method for the quantification of suspended sediments from AVHRR NOAA-11 satellite data, International Journal of Remote Sensing, 14(5): 885-894.

Gardner, J., W. Dean, and T. Vallier, 1980. Sedimentology and geochemistry of surface sediments, outer continental shelf, southern Bering Sea, Marine Geology, 35(4): 299-329.

Gibbs, R.J., M.D. Matthews, and D.A. Link, 1971. The relationship between sphere size and settling velocity, Journal of Sedimentary Petrology, 41(1): 7-18.

Kelly, M. and Tuxen, K, 2009. Remote Sensing and Geospatial Technologies for Costal Ecosystem Assessment and Management. Springer-Verlag Berlin Heidelberg pp. 341-363

Krone, R., 1987. A method for simulating historic marsh elevations, in Kraus, N. (Ed.), Coastal Sediments 87, American Society of Civil Engineers, New York, New York, pp. 316-323.

Krumbein, W.C. and L.L. Sloss, 1963. Stratigraphy and Sedimentation. W.H. Freeman Publishing. San Francisco, CA. pp. 660.

Li, R., Y. Kaufman, Bo-Cai Gao, and C. Davis, 2003. Remote sensing of suspended sediments and shallow coastal waters, IEEE Transactions on Geology and Remote Sensing, 41(3): 559-566.

Miller, R. L., and B. A. McKee, 2004. Using MODIS Terra $250 \mathrm{~m}$ imagery to map concentrations of total suspended matter in coastal waters, Remote Sensing of Environment, 93(1-2): 259-266.

Munday Jr., J. C., and T. T. Alföldi, 1979. LANDSAT test of diffuse reflectance models for aquatic suspended solids measurement, Remote Sensing of Environment, 8(2): 169-183.

Newcomer, M., A. Kuss, T. Ketron, A. Remar, V. Choksi, K. Grove, and J.W. Skiles, 2011. Modeling sediment deposition for predicting marsh habitat development, Proceedings for the American Society for Photogrammetry and Remote Sensing Conference, Milwaukee Wisconsin, May 3, 2011. 
NCDC, National Climate Data Center, 2010. National Environmental Satellite, Data, and Information Service, National Oceanic and Atmospheric Administration, http://www.ncdc.noaa.gov/oa/ncdc.html. (Accessed 10 July, 2010).

NOAA, National Oceanic and Atmospheric Administration, 2011. Tides and Currents. NOAA Predictions for Coyote Creek in Alviso Slough. http://tidesandcurrents.noaa.gov. (Accessed 10, July, 2010)

Pasternack, G. B., and G. S. Brush, 1998. Sedimentation cycles in a river-mouth tidal freshwater marsh, Estuaries and Coasts, 21(3): 407-415.

Pavelsky, T.M. and L.C. Smith. 2009. Remote Sensing of suspended sediment concentration, flow velocity, and lake recharge in the Peace-Athabasca Delta, Canada, Water Resources Research, 45: 1-16.

Philip Williams \& Associates, Ltd., 2005. Hydrodynamics and sediment dynamics: existing conditions report, South Bay Salt Pond Restoration Project, California State Coastal Conservancy, U.S. Fish \& Wildlife Service, California Department of Fish and Game, $88 \mathrm{pp}$.

Philip Williams \& Associates, Ltd, P. M., and P. M. Faber, 2004. Design guidelines for tidal wetland restoration in San Francisco Bay, The Bay Institute and California State Coastal Conservancy, Oakland, CA, 83 pp.

Reed, D. J., 1989. Patterns of sediment deposition in subsiding coastal salt marshes, Terrebonne Bay, Louisiana: the role of winter storms, Estuaries and Coasts, 12(4): 222-227.

Ruhl, C. A., D. H. Schoellhamer, R. P. Stumpf, and C. L. Lindsay, 2001. Combined use of remote sensing and continuous monitoring to analyze the variability of suspended-sediment concentrations in San Francisco Bay, California, Estuarine, Coastal and Shelf Science, 53(6): 801-812

SI Metric, 2010. Mass, Weight, Density, or Specific Gravity of Bulk Materials, SI Metric. [online] Available from: http://www.simetric.co.uk/si_materials.htm. (Accessed 9 August, 2010).

Siegel, S.W. and Bachand, P.A.M.. 2002. Feasibility Analysis of South Bay Salt Pond Restoration, San Francisco Estuary, California. ,San Rafael, CA. Wetlands and Water Resources.

Stumpf, R. P., and J. R. Pennock, 1989. Calibration of a general optical equation for remote sensing of suspended sediments on a moderately turbid estuary, Journal of Geophyical Research, 94(C10): 363-377.

Takekawa, J. Y., A. K. Miles, D. H. Schoellhamer, B. Jaffe, N. D. Athearn, S. E. Spring, G. G. Shellenbarger, M. K. Saiki, F. Mejia, and M. A. Lionberger, 2005. South Bay Salt Ponds Restoration Project, Short-term Data Needs, 2003-2005, Unpubl. Final Report, U.S. Geological Survey, Vallejo, CA, 270 pp. 
Temmerman, S., G. Govers, P. Meire, and S. Wartel, 2003. Modelling long-term tidal marsh growth under changing tidal conditions and suspended sediment concentrations, Scheldt estuary, Belgium, Marine Geology, 193(1-2): 151-169.

Temmerman, S., G. Govers, S. Wartel, and P. Meire, 2004. Modelling estuarine variations in tidal marsh sedimentation: response to changing sea level and suspended sediment concentrations, Marine Geology, 212(1-4): 1-19.

Teodoro, A., F. Veloso-Gomes, and H. Gonçalves, 2008. Statistical techniques for correlating total suspended matter concentration with seawater reflectance using multispectral satellite data, Journal of Coastal Research, 24(3): 40-49.

Trulio, L., D. Clarke, S. Ritchie, and A. Hutzel, 2007. South Bay salt pond restoration project: adaptive management plan, Final Environmental Impact Statement Report, South Bay Salt Pond Restoration Project, CA, 143 pp.

USGS, 2007. Continuous monitoring in the San Francisco Bay and Delta, U.S. Geological Survey. [online] Available from: http://sfbay.wr.usgs.gov/sediment/Cont_monitoring/index.html. (Accessed 14 June, 2010).

USGS, 2010a. Global Visualization Viewer, Earth Resources Observation and Science Center, (Glovis) http://glovis.usgs.gov/. (Accessed 10 July, 2010).

USGS, 2010b. Water quality monitoring of San Francisco Bay, U.S. Geological Survey. [online] Available from: http://sfbay.wr.usgs.gov/access/wqdata. (Accessed 14 June, 2010).

Wilde, I., F. Neural Networks, Mathematics Department, King's College London. [online] Available from: http:/homepage.ntlworld.com/ivan.wilde/notes/nn/nnnotespdf.pdf. (Accessed 19 August, 2010).

WIST, Warehouse Inventory Search Tool, 2010. Land Process Distributed Active Archive Center, National Aeronautics and Space Administration, https://lpdaac.usgs.gov/lpdaac/get_data/wist. (Accessed 22 July, 2010).

Zill, D.G., and M.R. Cullen. 2009. Differential Equations with Boundary Value Problems. $7^{\text {th }}$ Edition. Brooks/Cole Cengage Learning

Tables 


\begin{tabular}{cccccc}
\hline \hline Sensor & $\begin{array}{c}\text { Bands } \\
\text { Used }\end{array}$ & $\begin{array}{c}\text { Wavelengths } \\
(\mathbf{n m})\end{array}$ & $\begin{array}{c}\text { Resolution } \\
(\mathbf{m})\end{array}$ & Dates used & $\begin{array}{c}\text { Image } \\
\text { Source }\end{array}$ \\
\hline $\begin{array}{c}\text { ASTER } \\
\text { on Terra }\end{array}$ & $1,2,3$ & $520-860$ & 15 & $10 / 8 / 04,10 / 29 / 09$ & $\begin{array}{c}\text { Glovis } \\
\text { (USGS, } \\
2010 \mathrm{a})\end{array}$ \\
\hline $\begin{array}{c}\text { Landsat } 5 \\
\text { TM }\end{array}$ & $1,2,3,4$ & $405-900$ & 30 & $\begin{array}{c}8 / 18 / 94,8 / 22 / 07,8 / 27 / 09, \\
7 / 5 / 10,1 / 5 / 11\end{array}$ & Glovis \\
\hline
\end{tabular}

Table I Satellite sensors used to detect SSCs and corresponding dates 


\begin{tabular}{|c|c|c|}
\hline Variable & Field Collection Method & Laboratory Processing Technique \\
\hline $\begin{array}{l}\text { Suspended sediment } \\
\text { concentration }(\mathrm{mg} / \mathrm{L})\end{array}$ & Water samples from South Bay & Filtration \\
\hline Grain size distribution & Sediment samples from Pond A21 & Coulter LS100Q using laser diffraction \\
\hline Settling velocity $(\mathrm{cm} / \mathrm{s})$ & Sediment samples from Pond A21 & $\begin{array}{l}\text { Modified Gibbs equation (Gibbs et al. } \\
1971 \text { ) }\end{array}$ \\
\hline $\begin{array}{l}\text { Organic carbon content } \\
(\% \text { organic carbon })\end{array}$ & Sediment samples from Pond A21 & $\begin{array}{c}\mathrm{CO}_{2} \text { coulometer and combustion } \\
\text { chamber }\end{array}$ \\
\hline
\end{tabular}

Table II Variables used in the MARSED model, the field collection method for each variable, and the corresponding laboratory processing techniques. 


\begin{tabular}{c|c}
\hline \hline Variable & Average Value \\
\hline $\begin{array}{c}\text { Surface suspended sediment } \\
\text { concentration }(\mathrm{mg} / \mathrm{L})\end{array}$ & 46.16 \\
\hline Grain size $(\mu \mathrm{m})$ & 4.72 \\
\hline Settling velocity $(\mathrm{m} / \mathrm{s})$ & $5.06 \times 10^{-5}$ \\
\hline $\begin{array}{c}\text { Organic carbon content }(\% \text { organic } \\
\text { carbon })\end{array}$ & 2.08 \\
\hline Bulk density $\left(\mathrm{kg} / \mathrm{m}^{3}\right)$ & 1600 \\
\hline
\end{tabular}

Table III Average values of the field data collected in Pond A21. All data were analyzed in the USGS Western Coastal Marine Geology Laboratory. 


\begin{tabular}{lccc}
\hline \hline \multicolumn{1}{c}{ Sensor } & Linear & Multivariate & ANN \\
\hline \multicolumn{4}{c}{ Regressions } \\
\hline Landsat 5 TM & 0.83 (Band 3) & 0.84 & 0.69 \\
ASTER & 0.65 (Band 3) & 0.88 & 0.87 \\
\hline \multicolumn{4}{c}{ RMSD (mm) } \\
Landsat 5 TM & 120.41 & 186.84 & 131.83 \\
ASTER & 66.84 & 97.94 & 82.32 \\
\hline
\end{tabular}

Table IV Regressions are shown from the, linear, multivariate, and ANN statistical techniques for predicting SSCs. Root mean square deviation (RMSD) ( $\mathrm{mm}$ ) calculated between modeled and field results is also shown from comparisons with the field results. Note that the most accurate predicted dataset was derived from ASTER linear regression with an RMSD of $66.84 \mathrm{~mm}$. 
Figures

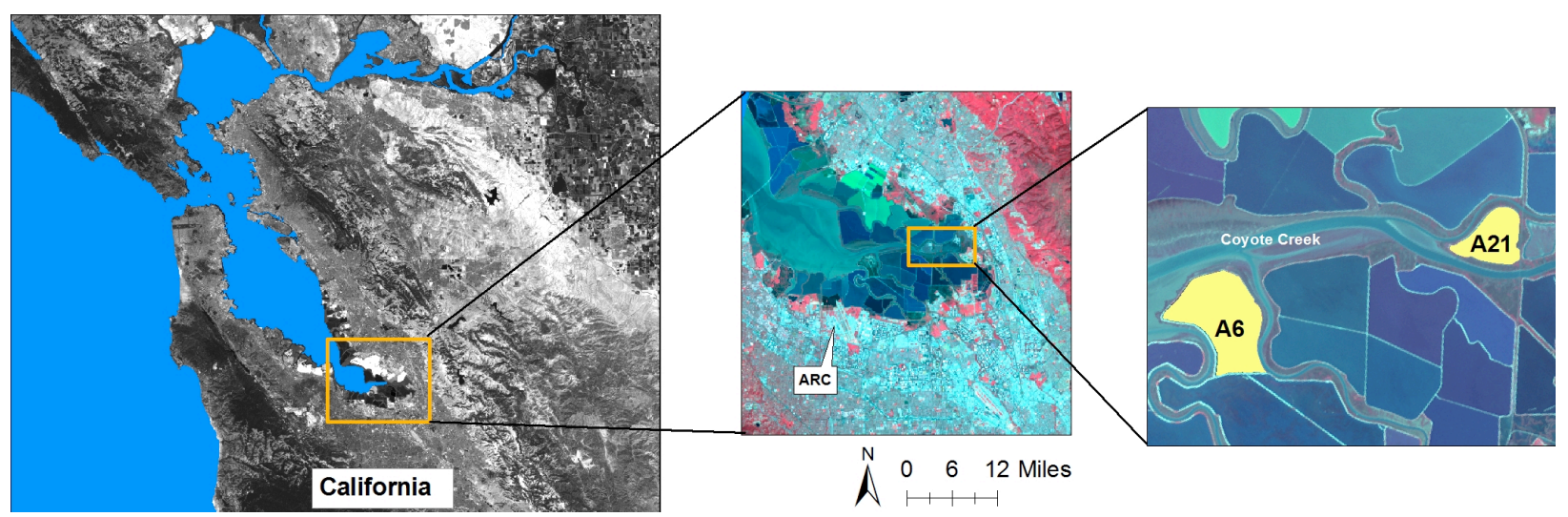

Fig. 1 Study location in the Alviso Complex in the San Francisco Bay, California. Ponds A21 and A6 are shown in yellow. Note also the location of Coyote Creek and NASA Ames Research Center (ARC). 


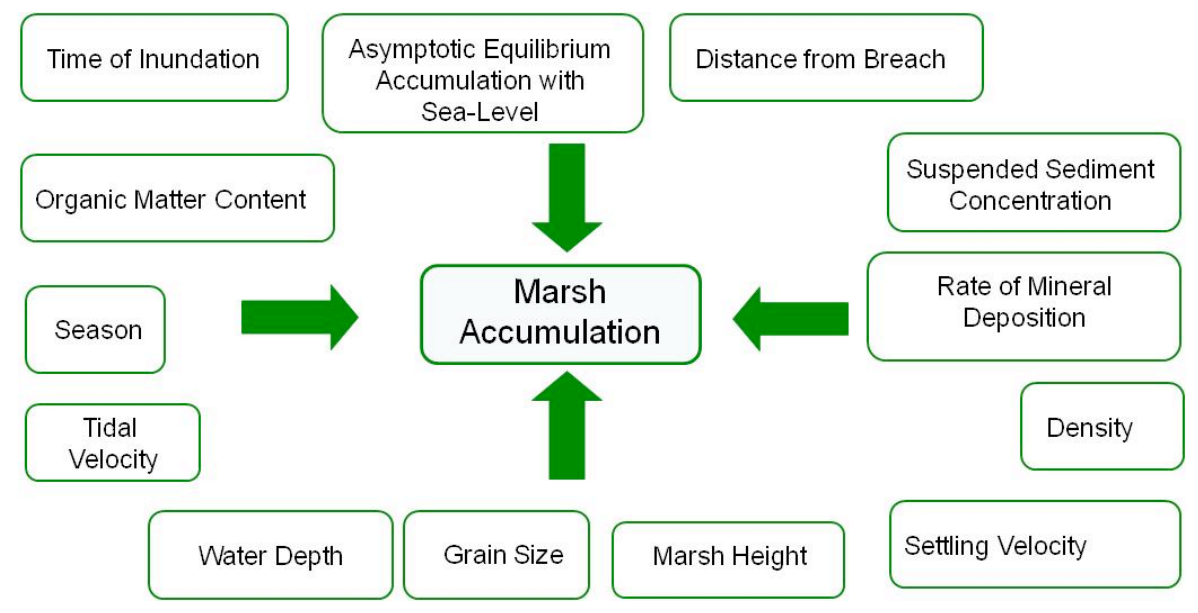

Fig. 2 Conceptual framework of variables contributing to marsh accumulation. All variables contribute to sediment deposition and are used in the MARSED model. 


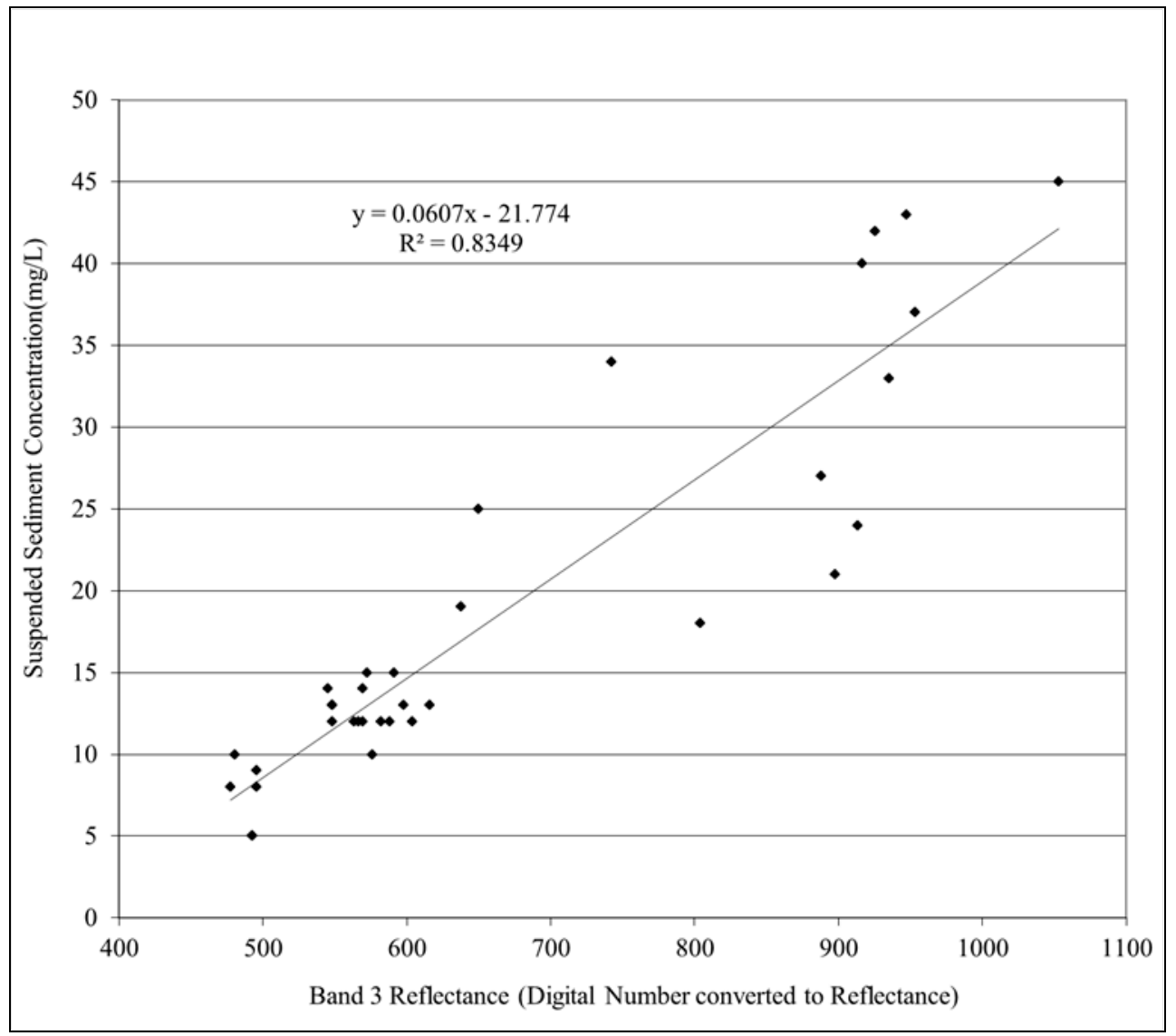

Fig. 3 Linear regression between suspended sediment concentrations combined from the USGS and from the field samples and the reflectance values from Landsat TM. Landsat band $3(630-690 \mathrm{~nm})$ reflection correlated with suspended sediment concentration. 


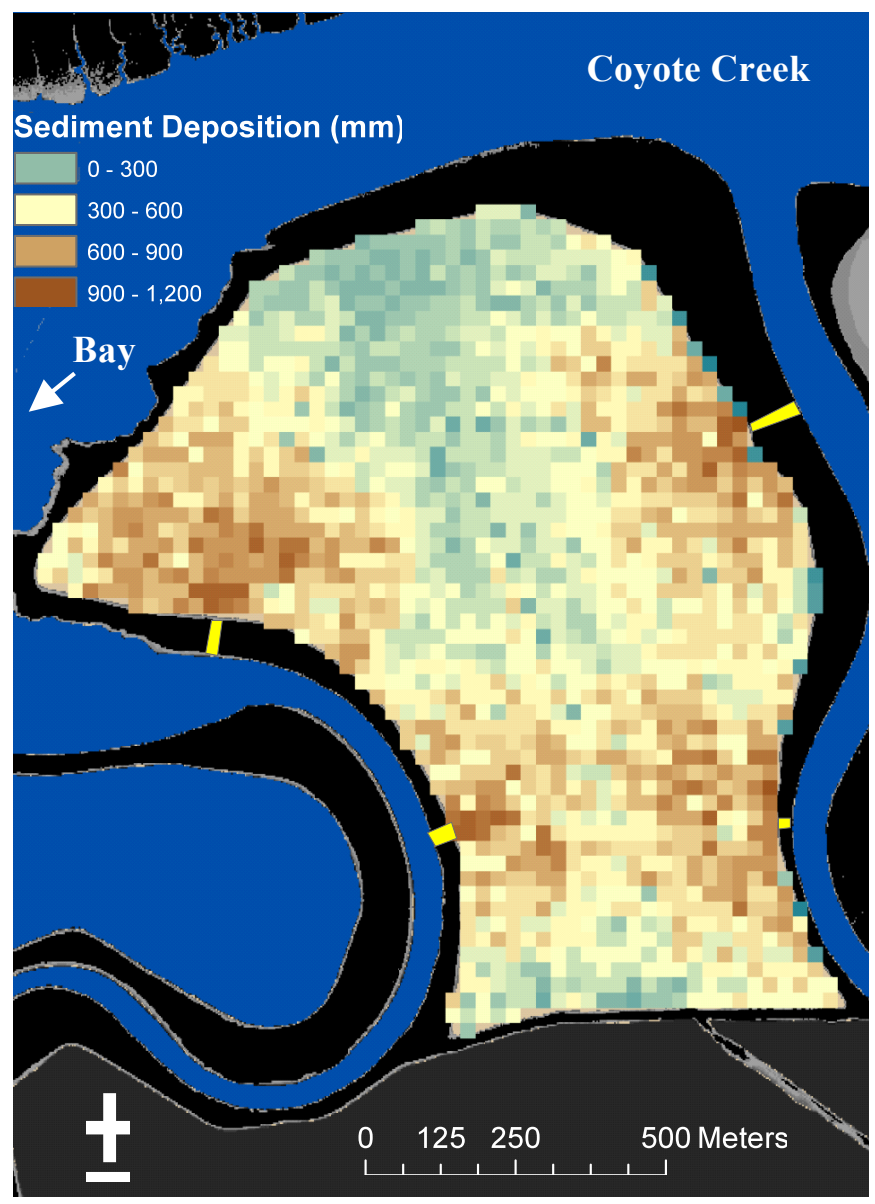

Fig. 4 Pond A6 showing sediment deposition in $\mathrm{mm}$. The locations of the levee breaches (yellow) are indicated. Also, the South Bay flows into Coyote Creek near Pond A6. 


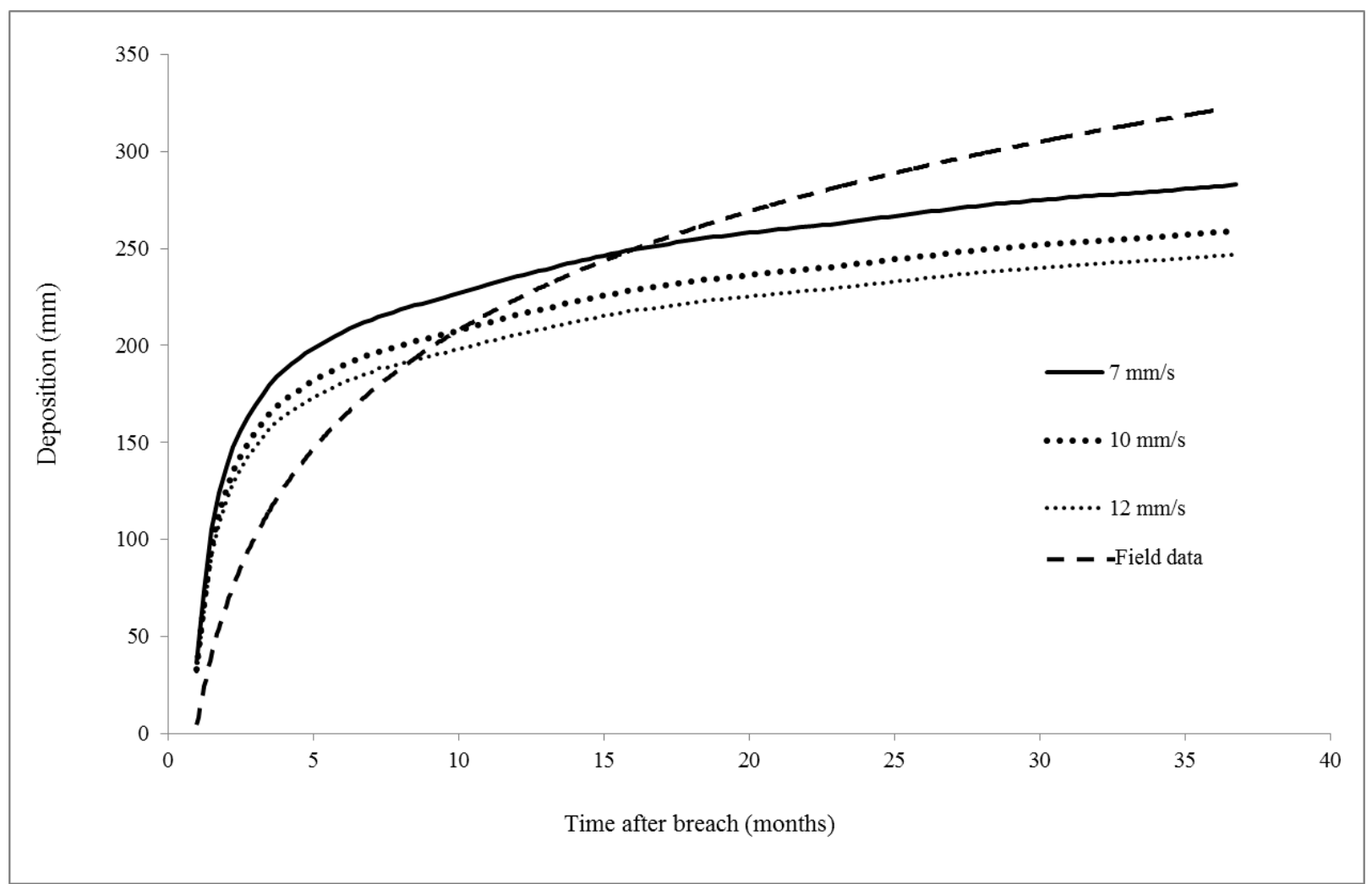

Fig. 5 MARSED model sensitivity to the input tidal velocity. 


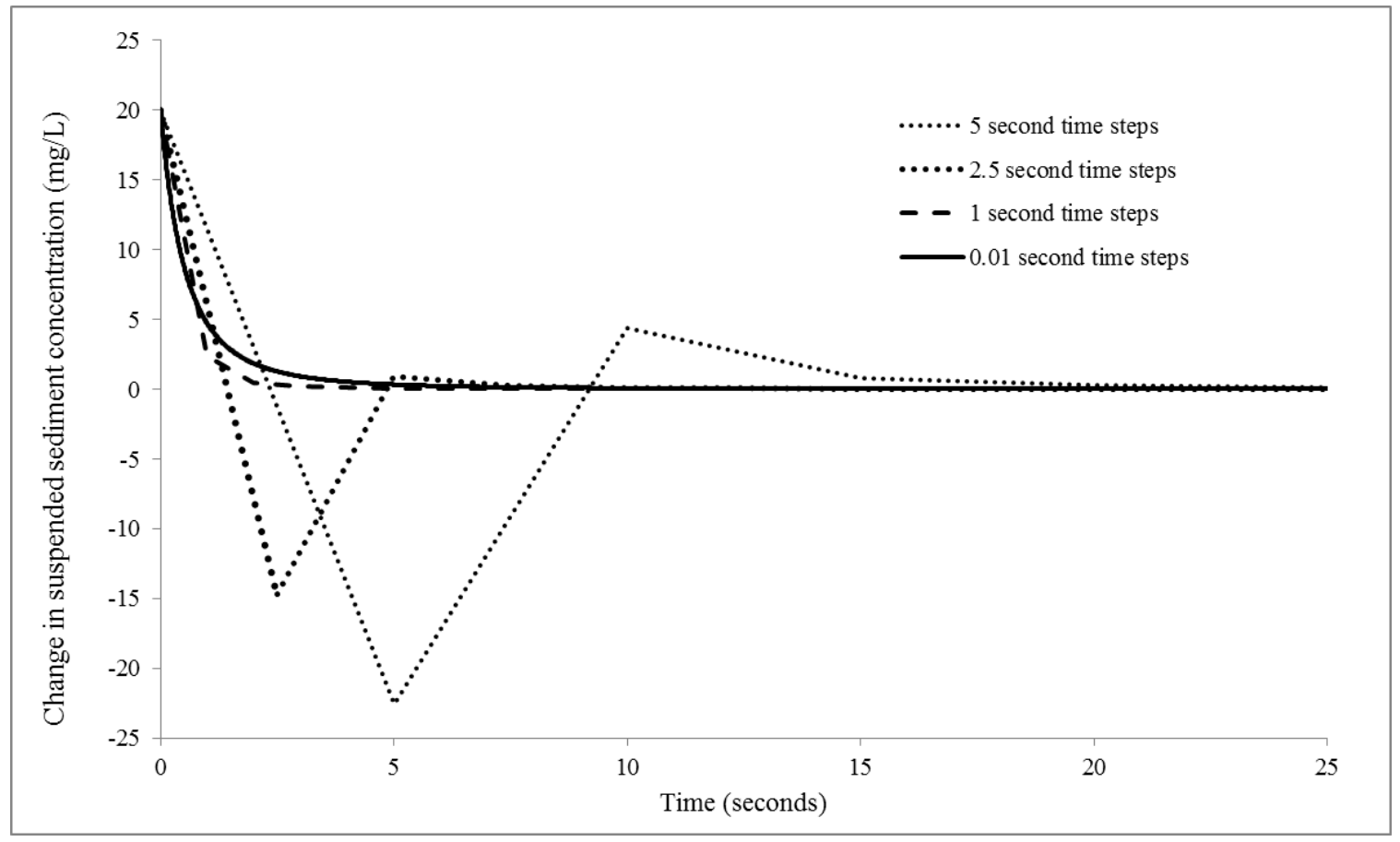

Fig. 6 Sensitivity of the MARSED model to the length of the time steps. Time steps of 0.01 seconds produces a relatively more stable curve than the other, and for accuracy purposes, a time step of $0.001 \mathrm{~s}$ was used in this study. 


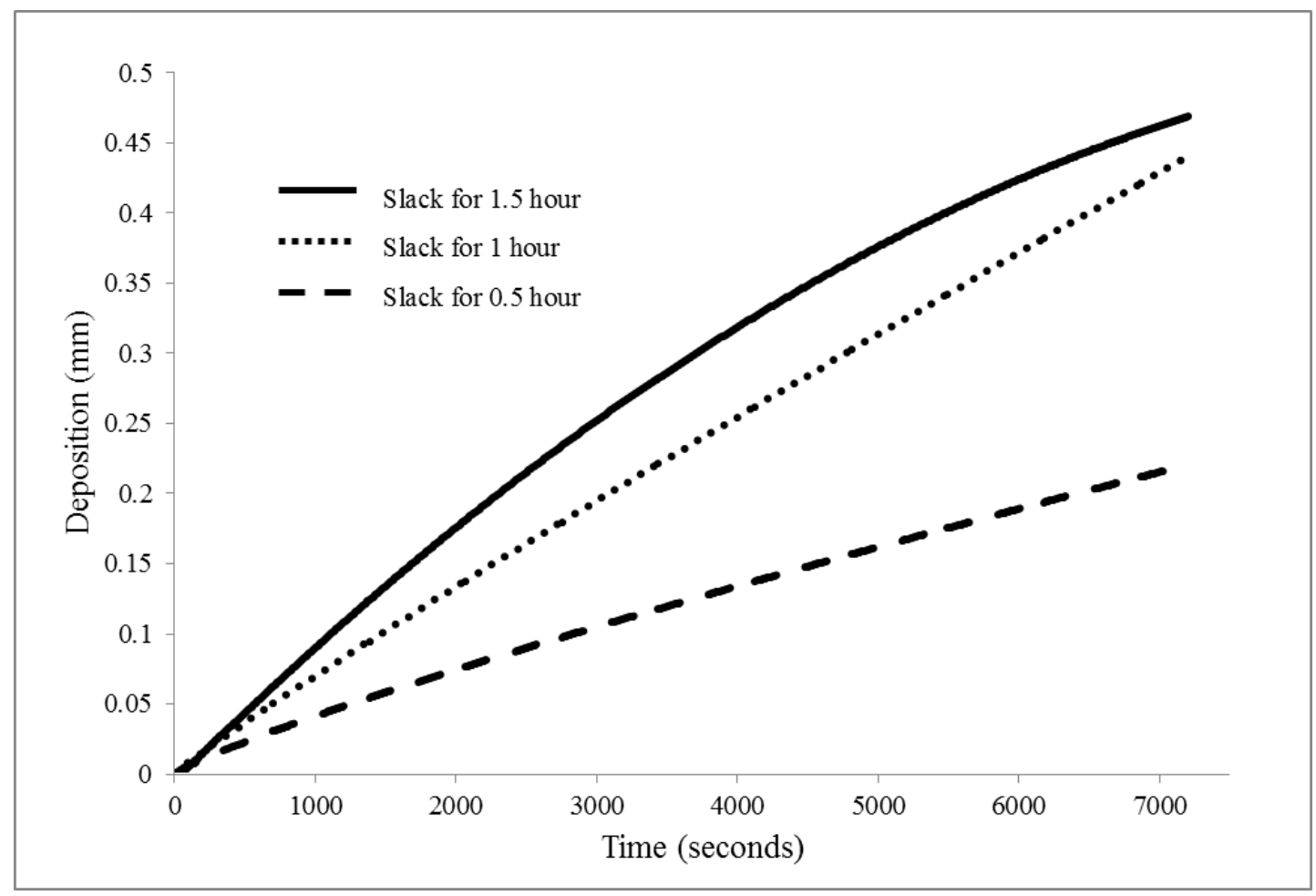

Fig. 7 Sensitivity of the MARSED model to the time of the slack period. Because tides vary each day, and because the ponds are shielded from large variations in tides, a slack period of 1.5 hours was chosen. 